\title{
Long-Run Relations Between Private and Public Sector Wages in Sweden ${ }^{1}$
}

\author{
TOR JACOBSON
}

Department of Statistics, Uppsala University, Box 513, 75120 Uppsala, Sweden

\author{
Menry Ohlsson \\ Department of Economics, Uppsala University, and, Department of Economics, University of \\ Michigan, Ann Arbor, MI 48109-1220, USA
}

\begin{abstract}
Using a maximum likelihood cointegration approach we find two long-run relationships between central government, local government, and private sector wages in Sweden. This means that there is one common trend for the three sectoral wages. Private sector wages are weakly exogenous for the estimation of the long-run relationships. This suggests that the private sector is the wage leader. Testing linear restrictions on the estimated cointegrating space, we reject stationarity for the three relative wages using likelihood ratio-tests. The hypotheses of homogeneity for the two cointegrating vectors, i.e., that wages do not diverge in the long run, is also rejected.
\end{abstract}

JEL Classification System-Numbers: C32, E24, J31

\section{Introduction}

Public sector employment has increased considerably in many countries. Wage formation in the public sector has, however, received less attention than private sector wage formation. The "Scandinavian Model of lnflation," in Sweden known as the EFO-model, has heavily influenced Scandinavian thinking about intersectoral wage linkages. ${ }^{2}$ A key assumption in this framework is that the tradeable sector (roughly corresponding to mining and manufacturing) acts as a

1 This work is partly financed by Tore Browaldhs Stiftelse. Henrik Hansen has kindly made a maximum likelihood cointegration routine for the RATS software available to us. We are indebted to Reinhold Bergström, Per-Anders Edin, Bertil Holmlund, Søren Johansen, Katarina Juselius, Anders Vredin, Anders Warne, and the referees for comments on previous drafts. The usual disclaimer applies. Previous versions of the paper, titeled "Cointegrating Sectoral Wages in Sweden," were presented at Econometric Society, European Meeting, Cambridge, UK, 1991 and the IRES, Université Catholique de Louvain, international workshop "Disaggregate labour markets," Wavre, Belgium, 1992.

2 The EFO-model was developed by the research department directors of TCO (the Central Organisation of Salaried Employees), SAF (the Swedish Employers' Confederation), and LO (the Swedish Trade Union Confederation); see Edgren et al. (1973). The analysis is similar to an earlier Norwegian analysis presented in Aukrust (1977). 
wage leader with respect to the nontradeable sector. In the long run nominal wages in the tradeable sector adjust to the "room" given by the sum of domestic productivity and world market prices. Wage levels in the tradeable sector transmit to the rest of the economy through bargaining institutions and market forces. Despite the widespread use of the EFO-model, there have been rew attempts to test the assumptions and predictions of the model.

Holmlund and Ohlsson (1992) offer some evidence for Sweden on wage linkages between private and public sectors. They find that wage increases in the private sector Granger cause public sector wage increases. Public sector wage movements also involve an error correction mechanism by which past deviations from the long-run relative wage path are offset. Their analysis concerns a three sector division of the economy; private sector, central government, and local governments. The estimated single equation models are, however, bivariate, i.e., only two sectors at a time are compared. The present paper extends the analysis by simultaneously taking wages in all three sectors into account. One problem with the single equation approach to cointegration is that it is not clear when valid inference is possible for the estimates of the cointegration relationships. We use an alternative method, maximum likelihood cointegration, which does make inference possible.

The objective of the paper is to test whether private sector wages in Sweden lead public sector wages. We also test how the wage levels in the three sectors move together in the long run. To this end, we estimate an error correction model using quarterly Swedish nominal wage data for the period $1968-1988$. $^{3}$ The focus is on long-run wage relationships and the possible impact of these relationships on wage changes. We concentrate the presentation to the estimated long-run effects although we also estimate the short run dynamics.

The paper is organized as follows: Section 2 gives the background by discussing the theoretical framework and some stylized facts about the changes in sectoral employment in Sweden during the last decades. Section 3 presents the empirical results, while section 4 summarizes our main findings. Some additional information about the estimations can be found in the Appendix.

\section{Background}

The EFO-model rests on two important assumptions. First, the model can be interpreted as a model of the main course, or the long-run path, of the economy

3 We compute average hourly wage rates using series from the National Accounts on paid out wages and salaries and total hours worked among employees. The sources are the SNEP-Q data base (1968-1969) and Statistics Sweden (unpublished tables, 1970-1988). SNEP-Q is a quarterly econometric model of the Swedish economy developed at Uppsala University and FIEF (Trade Union Institute for Economic Research). 
(the main course assumption). ${ }^{4}$ Second, the model also assumes that the variables will evolve in a corridor around the main course (the steady state). Deviations from the steady state will trigger off forces that will drive the variables back toward the steady state (the stability assumption). The model assumes that the domestic economy is a price taker on world markets. The "room" for (log) nominal wages in the tradeable sector, $w^{t}$, in the long run is:

$$
w^{t}=p^{t}+q^{t}
$$

where $p^{t}$ denotes (log) world market price for tradeables in domestic currency and $q^{i}$ denotes $(\log )$ productivity in the tradeable sector. Productivity is by assumption exogenous. Productivity and world market prices, therefore, give the main course for wages in the tradeable sector. Equation (1) implies that the factor shares of value added are constant in the long run. It lies close at hand to interpret the combination of the main course assumption and the stability assumption as an error correction model. Wage increases in the tradeable sector could be written as a single equation error correction model:

$$
\Delta w_{t}^{t}=\mu+\sum_{i=1}^{k-1}\left[\gamma_{1 i} \Delta w_{t-i}^{t}+\gamma_{2 i}\left(\Delta p_{t-i}^{t}+\Delta q_{t-i}^{t}\right)\right]+\pi\left[w_{t-k}^{t}-p_{t-k}^{t}-q_{t-k}^{t}\right]+\varepsilon_{t}
$$

where $\Delta$ denotes first differences, subindex $t$ denotes the period $t, k$ is the number of lags, $\mu$ is a constant, $\gamma_{1 i}, \gamma_{2 i}$, and $\pi$ are parameters, and $\varepsilon_{t}$ is an error term. The second term in brackets in (2) captures the error correction, deviations from the main course will affect wage changes so that the wage level will return to the steady state. Nymoen (1989) estimates error correction models similar to (2) to test whether Norwegian manufacturing wages are determined by domestic productivity and world market prices (also see Rödseth and Holden, 1990), while Warginger (1991) estimates similar models using Swedish data.

In a next step, wage levels in the tradeable sector are assumed to transmit to the rest of the economy through bargaining institutions and market forces. The tradeable sector will act as wage leader. The second steady state equation can be written:

$$
w^{n t}=w^{t}
$$

where $w^{n t}$ denotes the wage level in the nontradeable sector. The error correction representation of how wages in the tradeable sector affect wages in the nontradeable sector is:

$$
\Delta w_{i}^{n t}=\mu^{*}+\sum_{i=1}^{k-1}\left[\gamma_{i i}^{*} \Delta w_{t-i}^{n t}+\gamma_{2 i}^{*} \Delta w_{t-i}^{t}\right]+\pi^{*}\left[w_{t-k}^{n t}-w_{t-k}^{t}\right]+\varepsilon_{t}^{*}
$$

where the notation is analogous to (2). Our empirical analysis concerns equation (3) and equation (4) in the sense that we test the hypotheses of wage leader-

4 The model also can be given an open economy Phillips-curve interpretation, see, e.g., Calmfors (1978) and Lindbeck (1979). 
Table 1. Sectoral employment in Sweden, 1968 and 1988, percent of total employment

\begin{tabular}{lllll}
\hline & $\begin{array}{l}\text { private sector } \\
\text { manufacturing }\end{array}$ & services & $\begin{array}{l}\text { central } \\
\text { government }\end{array}$ & $\begin{array}{l}\text { local } \\
\text { government }\end{array}$ \\
\hline 1968 & 33 & 38 & 12 & 17 \\
1988 & 24 & 35 & 10 & 31 \\
\hline
\end{tabular}

Note: Private sector manufacturing refers to ISIC 2-4 while private sector services refers to ISIC 1,5-9

Source: Computations based on the Swedish labor force surveys.

ship and long-run equality between sectoral wages. We diverge from the original model in two fundamental ways. First, we start by estimating a multivariate error correction model instead of a single equation model like (4). This way we can test instead of imposing the wage leadership assumption. Second, we contrast the whole private sector (not separating tradeables and nontradeables) to the public sector (distinguishing between central and local government).

In 1968 the private sector answered for more than two thirds of total employment in Sweden, see Table 1. The share of manufacturing was only slightly lower than that for services. Two decades later the picture has radically changed. The public sector employment share is over 40 percent while only one fourth was employed in private sector manufacturing. These shifts have made the wage linkages between the private and the public sector more important. In addition, the private and public sectors, not tradeables and nontradeables, have been the main wage bargaining areas.

\section{The Empirical Analysis}

The statistical basis for our analysis of Swedish sectoral wages is multivariate cointegration analysis. ${ }^{5}$ Specifically, we use the maximum likelihood cointegration approach introduced by Johansen $(1988) .{ }^{6}$ Johansen postulates a finite vector autoregression of order $k$ as an adequate representation of the p-dimensional time series $X_{t}$ :

5 Cointegration, the analysis of non-stationary time series, has been a rapidly expanding area during the 1980s. Several survey articles have been published, see Campbell and Perron (1991) and Muscatelli and Hurn (1992). Also, the following journals have presented special issues on cointegration: Journal of Policy Modelling, 1992, Journal of Economic Dynamics and Control, 1988, and Oxford Bulletin of Economics and Statistics, 1986 and 1992.

6 Johansen (1991) provides further theoretical results, see also Ahn and Reinsel (1990). Johansen and Juselius (1990) provide an excellent introduction to the method and an illustrative application. Kunst and Neusser (1990) use the approach for the anaiysis of Austrian macroeconomic time series. 


$$
X_{t}=\Pi_{1} X_{t-1}+\Pi_{2} X_{t-2}+\cdots+\Pi_{k} X_{t-k}+\mu+\Phi D_{t}+\varepsilon_{t}, \quad(t=1, \ldots, T)
$$

where $\mu$ is a constant, $D_{t}$ are centered seasonal dummy variables orthogonal to $\mu$, and the errors $\varepsilon_{1}, \ldots, \varepsilon_{T}$ are iid $N_{p}[0, \Sigma]$. In our application the $X_{t}$-vector of (5) is:

$$
X_{t}=\left[\begin{array}{c}
w_{t}^{c} \\
w_{t}^{l} \\
w_{t}^{p}
\end{array}\right]
$$

where $w_{t}^{c}, w_{t}^{l}$, and $w_{t}^{p}$ are the logarithms of hourly wages in the central government (index $c$ ), the local government (index $l$ ), and the private sector (index $p$ ). ${ }^{7}$ Rewriting (5) slightly gives us the model in error correction form:

$$
\Delta X_{t}=\Gamma_{1} \Delta X_{t-1}+\Gamma_{2} \Delta X_{t-2}+\cdots+\Gamma_{k-1} \Delta X_{t-k+1}+\Pi X_{t-k}+\mu+\Phi D_{t}+\varepsilon_{t}
$$

where $\Gamma_{i}=-\left(I-\Pi_{1}-\cdots-\Pi_{i}\right), i=1, \ldots, k-1$ and $\Pi=-I+\Pi_{1}+\cdots+$ $\Pi_{k}$. The reduced rank implication of cointegration concerns the $I I$-matrix in (6). The model has three possible interpretations depending on $r=\operatorname{rank}(I T)$, the cointegrating rank. When $r=0,(6)$ is a correctly specified VAR in first differences since $\Pi=0$. If $r=p$, (5) is a correctly specified VAR in levels and, lastly, when $0<r<p$ we have the cointegration case that makes (6) interpretable as an error correction model. In our application we find that $r$ is less than $p$ when estimating (6). We are therefore dealing with an error correction model.

Now writing $\Pi=\alpha \beta^{\prime}$, where $\alpha$ and $\beta$ are full rank $(p \times r)$-matrices, estimation of (6), for given $\beta$, involves only stationary processes. According to Johansen's version of the Granger Representation Theorem (Johansen, 1991), $\beta^{\prime} X_{t-k}$ are the $r$ cointegrating relations of the system. ${ }^{8}$ These stationary relations, or error correction mechanisms, may affect each equation of the system differently. The rows of $\alpha$, which can be interpreted as vectors of "loadings" or "weights," reflects this.

To carry out the empirical analysis, we have to decide on the number of lags in (5), $k$. The essential criterion is that of observing serially uncorrelated residuals that are approximately normal, i.e., we want an estimated model such that the distributional assumptions for $\varepsilon_{t}$ in (5) are credible. The maximum

The three sectoral wages constitute the entire information set, i.e., we do not condition on exogenous variables such as, e.g., world market prices or the labor market situation. The reason for this is threefold; the current information set is sufficient for the objective of the paper, the fit of the statistical model is adequate, and we believe in a parsimonious attitude toward the number of estimated parameters since the sample is small.

8 The Granger Representation Theorem in Engle and Granger (1987) shows, i.a., the duality between the existence of an error correction model and the presence of cointegration between variables of the model. 
likelihood cointegration RATS-routine produces tests on the resicuals with respect to normality (Jarque and Bera, 1980) and autocorrelations (Box and Pierce, 1970). Sample skewness and excess kurtosis are also calculated. These statistics are univariate, i.e., they consider the residuals of each equation in turn. The procedure stands in contrast with the multivariate nature of the maximum likelihood cointegration method and the problem as such.

Jacobson (1991) explores the possibilities of using multivariate information criteria and multivariate portmanteau testing in a Monte Carlo study of a cointegrated system. He finds that the multivariate statistics can be useful, at least as a complement to univariate testing. Specifically, the results suggest that the iterated logarithm criterion (LIL), due to Hannan and Quinn (1979), is comparatively accurate. The Akaike information criterion (AIC), due to Akaike (1969), often overstates the correct order while the logarithm criterion (BIC), due to Schwarz (1978), often understates the correct order, at least in small samples. LIL also tends to understate the correct order to some extent.

Jacobson also found that the multivariate portmanteau statistic, see, e.g., Hosking (1980), applied on cointegrated time series has an approximate $\chi^{2}$ distribution under the null with $p^{2}(s-k)$ degrees of freedom, where $s$ is the number of autocorrelations. The statistic simplifies to an ordinary Box-Pierce test in the univariate case. As for the assumption of normality, Mardia (1970) defines multivariate measures of skewness, $\hat{b}_{1, p}$, and kurtosis, $\hat{b}_{2, p}$, for a $p$-dimensional process. Moreover, Mardia suggests two asymptotic tests for departures from multinormality based on the two measures. $\hat{Q}_{\text {skew }}$, calculated from $\hat{b}_{1, p}$, is asymptotically $\chi^{2}$ with 10 degrees of freedom for $p=3$ while $\hat{Q}_{\mathrm{kur}}$ is standard normal in the limit.

Table 2 contains the results of the multivariate testing for lag order in our data set. Minimizing values for AIC, BIC, and LIL suggest that four, two, and two lags, respectively, should be included in the model. The portmanteau tests result in rejection for the null hypothesis of uncorrelated residuals when $k=1$, borderline significance for $k=2$ and $k=3$ using a test size of 1 percent, while $k=4$ and $k=5$ are clearly insignificant. The multinormal tests are all insignificant, except $\hat{Q}_{\mathrm{kur}}$, the kurtosis statistic, when $k=4$.

Three lag order candidates therefore emerge. Despite the outcome of BIC and LIL, which have a tendency to suggest to few lags, we reject $k=2$. The reason is the inadequate fit, as reflected to some extent by the portmanteau test, and even more so by the univariate tests of the residuals (not reported). The assumptions of the error term in (5) seem equally fulfilled for lag orders 3 and 4 . A parsimonious strategy points toward $k=3$ as the reasonable choice.

\section{The Basic Model}

Table 3 presents the results of univariate normality tests when the model in (6) is estimated with 3 lags. We find that the assumptions for the error term 


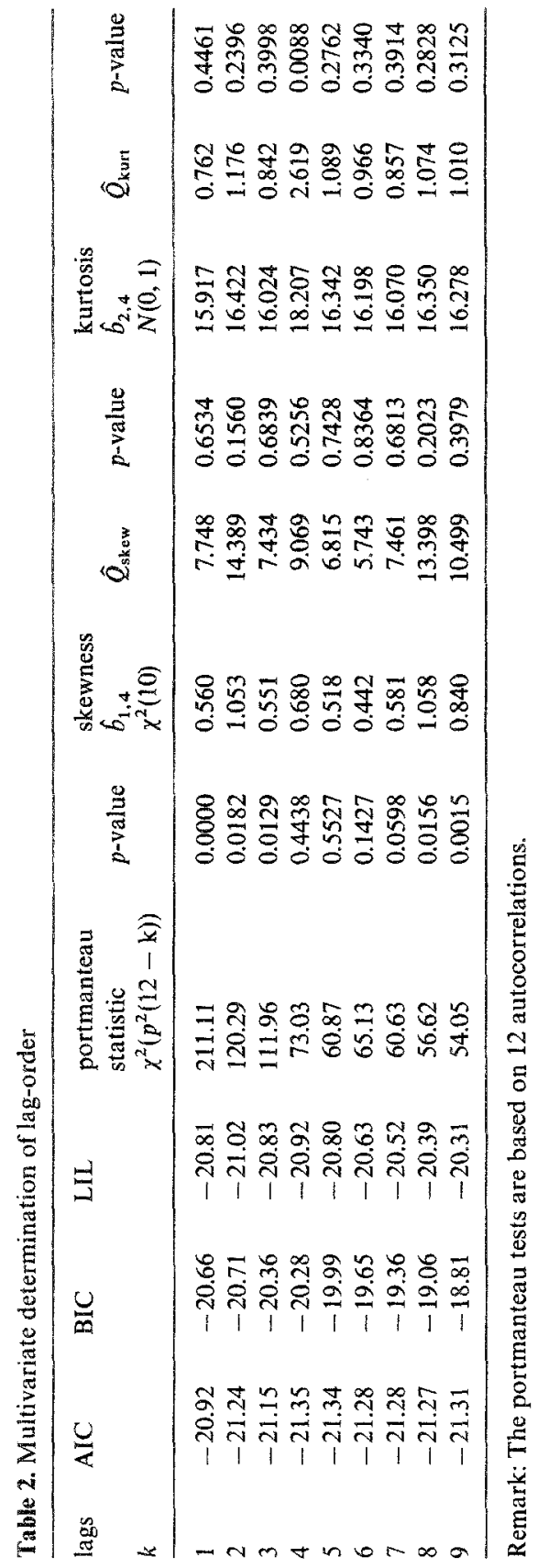


Table 3. Univariate testing of residuals in model (6) using $k=3$

\begin{tabular}{lllllll}
\hline $\begin{array}{l}\text { dependent } \\
\text { variable, } \\
\text { first } \\
\text { difference of }\end{array}$ & skewness & $\begin{array}{l}\text { excess } \\
\text { kurtosis }\end{array}$ & $\begin{array}{l}\text { normality } \\
\chi^{2}(2)\end{array}$ & $p$-value & $\chi^{2}(9)$ & $p$-value \\
\hline $\begin{array}{l}\text { central gov } \\
\text { wages }\end{array}$ & 0.424 & 1.255 & 7.747 & 0.0208 & 8.312 & 0.5030 \\
$\begin{array}{l}\text { local gov } \\
\text { wages }\end{array}$ & 0.111 & -0.646 & 1.574 & 0.4552 & 6.631 & 0.6755 \\
$\begin{array}{l}\text { private sec } \\
\text { wages }\end{array}$ & 0.284 & 0.008 & 1.087 & 0.5807 & 19.259 & 0.0231 \\
\hline
\end{tabular}

Remark: The Box-Pierce tests are based on 12 autocorrelations.

in (5) are approximately fulfilled. The null of normality in the central government equation is rejected and so is the assumption of no serial correlation in the private wage equation. These problems are, however, not serious as they do not appear in our final, preferred model.

We will go on by presenting an estimate of the impact matrix $\Pi$ in (6) without any restrictions imposed, see Table 4 . Wage changes in central government are primarily affected by the own wage level and the level in local government. Local government and private sector wage levels are the important determinants of local government wage changes. The coefficients of the equation for private sector wage changes are small in comparison to the coefficients of the other two equations. This suggests that the error correction component is less important for the determination of private wages.

The estimated model is dynamically stable. All eigenvalues of the appropriate, stacked coefficient matrix based on $\hat{\Pi}_{1}, \hat{\Pi}_{2}$, and $\hat{\Pi}_{3}$ in (5) are within the unit circle. ${ }^{9}$ The largest eigenvalue is, however, almost unity $(0.9953)$, indicating that the unit root approach is appropriate for this application.

Table 4. The impact matrix $\hat{f}$ without cointegrating restrictions imposed

\begin{tabular}{|c|c|c|c|}
\hline \multirow{2}{*}{$\begin{array}{l}\text { dependent } \\
\text { variable, } \\
\text { change in }\end{array}$} & \multicolumn{3}{|c|}{ independent variable, level of } \\
\hline & central gov wages & local gov wages & private sec wages \\
\hline $\begin{array}{l}\text { central gov } \\
\text { wages }\end{array}$ & -1.161 & 0.738 & 0.365 \\
\hline $\begin{array}{l}\text { local gov } \\
\text { wages }\end{array}$ & 0.209 & -0.601 & 0.375 \\
\hline $\begin{array}{l}\text { private sec } \\
\text { wages }\end{array}$ & -0.144 & 0.045 & 0.085 \\
\hline
\end{tabular}

9 By appropriate, stacked coefficient matrix we refer to the VAR(1)-representation suitabie for examination of the stability properties of the system. 


\section{The Restricted Model}

Investigating the cointegrating rank of $\hat{I}=\hat{\alpha} \hat{\beta}^{\prime}$ amounts to posing the question: How many of potentially three vectors span the cointegrating space? The question is formalized by use of two likelihood ratio tests, the trace test and the maximum eigenvalue test, derived in Johansen $(1988,1991)$. Since cointegration implies reduced rank of $\Pi$, the intuition of testing for cointegrating rank $r$ is evaluation of the number of eigenvalues of $\hat{\Pi}$ that are close to zero. The two likelihood ratio statistics are trace $=-T \sum \ln \left(1-\hat{\lambda}_{i}\right)$ and $\max E V=$ $-T \ln \left(1-\hat{\lambda}_{i}\right)$ where $\hat{\lambda}_{i}$ is the eigenvalue associated with the eigenvector $\hat{v}_{i}$, which, in turn, is the $i$ th cointegrating vector $\hat{\beta}_{i}$ if $\hat{\lambda}_{i}$ is found to be non-zero. $\hat{\lambda}_{i}$ and $\hat{v}_{i},(i=1, \ldots, p)$, are the solutions of the eigenvalue problem implied by maximum likelihood estimation of model (6).

Using a standard 5 percent significance level leaves us with $r=2$ and thus two cointegrating vectors, see Table 5 . The graphs of the three potentially cointegrating vectors $\left(\hat{v}_{i}^{\prime} X_{t}, i=1,2,3\right)$ shown in the Appendix support this view. The first two are reasonably stationary while the third certainly is not.

The dual of this result is that there is one common stochastic trend for these variables. The main course assumption of the EFO-model suggests that wages in the tradeable sector in the long run are driven by the sum of world market prices and domestic productivity. In other words, the sum of these two factors gives the one main course for the economy. Finding one common trend in our data set is, therefore, consistent with the main course theory. We will not further pursue the point here but intend to return to the issue on future research.

Having settled for $r=2$, we take $\hat{\alpha}$ and $\hat{\beta}$ to be

$$
\hat{\alpha}=\left[\begin{array}{rr}
-0.017 & 0.013 \\
0.005 & 0.012 \\
-0.002 & 0.003
\end{array}\right], \quad \hat{\beta}=\left[\begin{array}{rr}
62.356 & -6.186 \\
-61.810 & -26.374 \\
1.320 & 30.543
\end{array}\right]
$$

The columns of $\hat{\beta}$ are the two cointegrating vectors while $\hat{\alpha}$ should be interpreted row wise. The first row contains the loadings or weights showing the relative importance of $\hat{\beta}^{\prime} X_{t}$ for the change in central government wages.

Table 5. Test statistics for the number of cointegrating vectors, critical values corresponding to a test size of 5 percent

\begin{tabular}{rrrrrr}
\hline$r$ & $\hat{\lambda}_{r+1}$ & $\max E V$ & $\begin{array}{l}\text { critical } \\
\text { value }\end{array}$ & trace & $\begin{array}{l}\text { critical } \\
\text { value }\end{array}$ \\
\hline 0 & 0.3307 & 32.52 & 18.14 & 47.33 & 25.49 \\
1 & 0.1547 & 13.61 & 11.93 & 14.80 & 13.19 \\
2 & 0.0146 & 1.19 & 3.93 & 1.19 & 3.93 \\
\hline
\end{tabular}

Remark: Critical values are from Jacobson and Larsson (1991). 
As is clear from the $\hat{\beta}$-matrix above, central government and local government wage levels $(62.3$ and -61.8$)$ are the important elements in the first cointegrating vector. Wage levels in the private sector dominate the second vector. Also note from the $\hat{\alpha}$-matrix that the largest loadings $(-0.017$ for the first vector and 0.013 for the second) are associated with central government wage changes.

The matrices $\hat{\alpha}$ and $\hat{\beta}$ result in the following restricted $\hat{\Pi}$-matrix:

$$
\hat{\Pi}=\alpha \hat{\beta}^{\prime}=\left[\begin{array}{rrr}
-1.161 & 0.738 & 0.365 \\
0.208 & -0.601 & 0.377 \\
-0.152 & 0.043 & 0.098
\end{array}\right]
$$

This $\hat{\Pi}$-matrix is very similar to that of the unrestricted model in Table 4. The only differences concern the private wage change equation in the last row.

The rest of the section is devoted to inference on what Johansen and Juselius (1992) call structural hypotheses, i.e., we will test the validity of imposing linear restrictions on $\hat{\alpha}$ and on $\hat{\beta}$. We also will test whether some given vector, say $\beta_{0}$, can be found in the cointegrating space.

\section{The Conditional Model - Weak Exogeneity}

It is natural to start by considering a restricted loadings matrix $\propto$. Johansen (1992) shows that testing the hypothesis that, e.g., the first row of $\alpha$ is zero is equivalent to testing the first equation for weak exogeneity with respect to the estimation of $\alpha$ and $\beta$. If the hypothesis cannot be rejected the so called partial VAR model is equivalent to the full system model. In other words, we can reduce the number of equations to $p-1$ and estimate the remaining equations conditional on the first. The model will then consist of $p-1$ endogenous nonstationary variables and one exogenous nonstationary variable. If all rows of $\alpha$ but one are zero, i.e., all variables but one being weakly exogenous in the system, we may resort to single equation analysis. This will be as efficient as the full system method for the estimation of $\beta$.

Moreover, it will in this situation suffice with regression to reach $\hat{\beta}$. The limitation is that should the true cointegrating rank be two or more, then single equation analysis will only come up with a linear combination of the actual cointegrating vectors. As given by various theorems in Johansen (1992), regression will do when the number of equations, $m$, in the partial VAR model is less or equal to the dimension of the cointegrating space. For $m \geq r$ we have to estimate $\beta$ by solving the eigenvalue problem as described previously.

Table 6 contains asymptotically $\chi^{2}$-distributed likelihood ratio test statistics for weak exogeneity. The null hypotheses of no impact on changes in private sector wages from disequilibrium errors $\left(\beta^{\prime} X_{t}\right)$ cannot be rejected. It is therefore reasonable to model the variable as weakly exogenous in the system. We will 
Tabie 6. Linear restrictions on $\alpha$ in the restricted model

\begin{tabular}{lcc}
\hline restriction & $L R$-statistic $\sim \chi^{2}(2)$ & $p$-value \\
\hline$\alpha_{1 i}=0, i=1,2$ & 20.689 & 0.0000 \\
$\alpha_{2 i}=0, i=1,2$ & 13.417 & 0.0012 \\
$\alpha_{3 i}=0, i=1,2$ & 2.257 & 0.3235 \\
\hline
\end{tabular}

Table 7. Various testing of the conditional model

\begin{tabular}{llllll}
\hline \multicolumn{2}{l}{ Test statistics for the number of cointegrating vectors } \\
\hline$r$ & \multirow{2}{*}{$\begin{array}{l}\max E V \\
r+1\end{array}$} & $\begin{array}{l}\text { critical } \\
\text { value }\end{array}$ & trace & $\begin{array}{l}\text { critical } \\
\text { value }\end{array}$ \\
\hline 0 & 0.3255 & 31.90 & 11.93 & 43.88 & 13.19 \\
1 & 0.1374 & 11.98 & 3.93 & 11.98 & 3.93 \\
\hline
\end{tabular}

Multivariate testing of residuals

\begin{tabular}{lll}
\hline portmanteau $\sim \chi^{2}(36)=44.175$ & $p$-value $=0.1645$ \\
$\hat{b}_{1,2}=0.1204$ & $\hat{Q}_{\text {skew }} \sim \chi^{2}(4)=1.6253$ & $p$-value $=0.8042$ \\
$\hat{b}_{2.2}=8.8279$ & $\hat{Q}_{\text {kur }} \sim N(0,1)=0.9314$ & $p$-value $=0.3516$ \\
\hline
\end{tabular}

Univariate testing of residuals

\begin{tabular}{lllllll}
\hline $\begin{array}{l}\text { dependent } \\
\text { variable }\end{array}$ & skewness & $\begin{array}{l}\text { excess } \\
\text { kurtosis }\end{array}$ & $\begin{array}{l}\text { normality } \\
\chi^{2}(2)\end{array}$ & $p$-value & $\chi^{2}(9)$ & $p$-value \\
\hline$\Delta w_{t}^{c}$ & 0.176 & 0.862 & 2.927 & 0.2314 & 13.166 & 0.1552 \\
$\Delta w_{t}^{l}$ & 0.172 & -0.492 & 1.219 & 0.5436 & 6.111 & 0.7288 \\
\hline
\end{tabular}

consider a reduced system consisting of the two equations for central and local government wages and estimate these conditional on private sector wages. The gain is a smaller system with fewer parameters to estimate without loss of information.

It lies close at hand to interpret the exogeneity tests as tests for wage leadership. The results suggest that public sector wage changes follow those of the private sector. Although the EFO-model does not deal with the interaction between private sector and public sector wages, the result that the private sector leads the public sector is in the spirit of the EFO-model.

Table 7 presents the results of specification testing of the conditional model using a lag order of $k=3$. We may conclude that $r=2$ and that the residuals have desired properties. The estimates in the conditional model are: 


$$
\begin{aligned}
& \hat{\alpha}=\left[\begin{array}{rr}
-0.015 & 0.011 \\
0.006 & 0.010
\end{array}\right], \quad \hat{\beta}=\left[\begin{array}{rr}
62.260 & -10.102 \\
-63.187 & -22.965 \\
2.670 & 31.105
\end{array}\right] \\
& \hat{\Pi}=\hat{\alpha} \hat{\beta}^{\prime}=\left[\begin{array}{rrr}
-1.070 & 0.710 & 0.311 \\
0.277 & -0.622 & 0.335
\end{array}\right]
\end{aligned}
$$

The estimates of the short-run dynamics are presented in the Appendix. The two cointegrating vectors can be normalized so that the long-run relations can be written:

$$
w_{t}^{c}=1.015 w_{t}^{l}-0.043 w_{t}^{p} \text { and } w_{t}^{l}=1.354 w_{t}^{p}-0.440 w_{t}^{c}
$$

The first relation, in particular, suggests a bivariate relationship between public sector wages. This is one restriction that will be tested below.

Before we carry on with the analysis of the cointegration space $\beta$ in the conditional model, we might add that testing for weak exogeneity here leads to rejection for both equations. Single equation analysis of the present data set would therefore be less efficient compared to the maximum likelihood approach.

\section{The Conditional Model with Restrictions - Homogeneity}

The first part of inference making will deal with hypotheses concerning the existence of prespecified vectors $\left(\beta_{0}\right)$ in the cointegrating space. Since any linear combination of two cointegrated vectors is also cointegrating, we now ask if it is possible to combine the vectors of the estimated space $(\beta)$ to reach a vector "known" to us. We use the likelihood ratio-principle to calculate test statistics that are $\chi^{2}(1)$ asymptotically. None of the included variables is stationary, see Table $8 .{ }^{10}$ The same story emerges when we consider the differences in wages

Table 8. Testing for the existence of prespecified vectors in the conditional model

\begin{tabular}{llll}
\hline hypothesis & vector & $L R$-statistic $\sim \chi^{2}(1)$ & $p$-value \\
\hline$w_{t}^{c} \sim I(0)$ & $\beta_{0}^{\prime}=\left[\begin{array}{lll}1 & 0 & 0\end{array}\right]$ & 11.945 & 0.0005 \\
$w_{t}^{l} \sim I(0)$ & $\beta_{0}^{\prime}=\left[\begin{array}{lll}0 & 1 & 0\end{array}\right]$ & 11.948 & 0.0005 \\
$w_{t}^{p} \sim I(0)$ & $\beta_{0}^{\prime}=\left[\begin{array}{lll}0 & 0 & 1\end{array}\right]$ & 11.976 & 0.0005 \\
$w_{t}^{c}-w_{t}^{l} \sim I(0)$ & $\beta_{0}^{\prime}=\left[\begin{array}{lll}1 & -1 & 0\end{array}\right]$ & 11.945 & 0.0005 \\
$w_{t}^{c}-w_{t}^{p} \sim I(0)$ & $\beta_{0}^{\prime}=\left[\begin{array}{lll}1 & 0 & -1\end{array}\right]$ & 7.995 & 0.0047 \\
$w_{t}^{l}-w_{t}^{p} \sim I(0)$ & $\beta_{0}^{\prime}=\left[\begin{array}{lll}0 & 1 & -1\end{array}\right]$ & 5.531 & 0.0187 \\
\hline
\end{tabular}

10. We have also tested the variables for seasonal integration using the procedures proposed in Hylleberg et al. (1990). When deterministic seasonals are included, the hypotheses of seasonal unit roots are rejected for all series while the hypotheses of zero frequency unit roots cannot be rejected. 
Table 9. Linear restrictions on $\beta$ in the conditional model

\begin{tabular}{lll}
\hline restriction & $L R$-statistic $\sim \chi^{2}(2)$ & $p$-value \\
\hline$\beta_{i 1}=0, i=1,2$ & 31.446 & 0.0000 \\
$\beta_{i 2}=0, i=1,2$ & 29.812 & 0.0000 \\
$\beta_{i 3}=0, i=1,2$ & 12.112 & 0.0023 \\
\hline$\beta_{i 1}+\beta_{i 2}+\beta_{i 3}=0, i=1,2$ & 14.787 & 0.0006 \\
\hline
\end{tabular}

between the three sectors. In other words, the hypotheses that there exist three bivariate relationships between wages in the three sectors are rejected.

Next we consider linear restrictions on $\beta$ and, again, this involves the likelihood ratio-principle and an asymptotic $\chi^{2}$-distribution as described in, e.g., Johansen and Juselius (1990). The first part of Table 9 concerns testing whether any variable is superfluous in the cointegrating vectors. The table reveals that the hypotheses are rejected, i.e., all variables should be included in the cointegration relationships.

Another restriction of interest is $\beta_{i 1}+\beta_{i 2}+\beta_{i 3}=0(i=1,2)$, i.e., that the coefficients for the wage level in each sector sum to zero in both vectors. Should these homogeneity restrictions hold, it implies that the wage levels in the three sectors do not diverge in the long run. Note that it follows from Table 8 that the vector $\left[\begin{array}{lll}1 & 1 & -2\end{array}\right]$ gives a nonstationary linear combination of the variables in levels. The last row of Table 9 presents the result of the homogeneity test. The hypothesis must be rejected. The test result is, therefore, not consistent with the wage homogeneity predictions of the EFO-model.

The sums of the estimated coefficients, [65.0-63.2] and [31.1 - 33.1], are, however, close to zero compared to the values of the coefficients. Why then is homogeneity rejected using the likelihood ratio-test? An insufficient sample size is a possible explanation. In a simulation study, Jacobson (1992) finds that the likelihood ratio-test of linear restrictions on $\beta$ may display an excess size under the null. This is a feature that becomes more pronounced the smaller the sample is. In other words, a large likelihood ratio-statistic can be recorded, in spite of a true null hypothesis, more often than desired when the sample is small. The problem of excess size under the null also affects the tests of the bivariate, unit coefficient wage relationships reported in Table 8.

\section{Concluding Remarks}

In this paper we have tested hypotheses of wage leadership and wage homogeneity using Swedish sectoral wage data for the private sector, the central government, and the local government sector. We have identified the long-run 
relationships between sectoral wages, studied the impact of these relationships on sectoral wage changes, and tested hypotheses concerning the relationships. Our main results are:

First, we find two long-run relationships between the wages in the three sectors. The main sectoral wages in the first are central and local government wages, while the private sector is more important than central and local government in the second. The dual of finding two long-run relationships between three variables is that there is one common trend for the wage variables. This is consistent with main course theories such as the EFO-model, where the main course is given by the sum of world market prices and domestic productivity in the tradeable sector.

Second, we go on by testing the model when we have imposed the restriction that there are two cointegrating vectors. Private sector wages are found to be weakly exogenous in the system. This suggests that the private sector wages lead public sector wages. Private sector wage leadership is in the spirit of the EFOmodel.

Third, we test the model when we have imposed the restrictions that there are two cointegrating vectors and that private sector wages are exogenous. We expect that the wage levels in the three sectors do not diverge in the long run. This implies that the cointegrating vectors are homogeneous, i.e., that the wage level coefficients simultaneously sum to zero. We must, however, reject the hypothesis. This may be because there is a size problem in small samples for the likelihood ratio-test of linear restrictions on cointegrating vectors, i.e., a true hypothesis is overrejected.

Our summarizing conclusion is, however, that sectoral wages in Sweden have evolved in a way consistent with what the main course approach predicts. Employers' organizations and trade unions in the private sector have sometimes argued that the public sector has been (but should not be) wage leader. We cannot, however, find any evidence that this is an accurate general description of the wage linkages between the private and the public sectors in Sweden.

\section{Appendix The Cointegrating Relations and the Estimated Short-Run and Long-Run Dynamics of the Conditional Model}

In this appendix we present graphs of the three time series generated by the eigenvectors and the level variables in the basic model. The first two are taken to be the cointegrating relations. The first, see Figure 1, has comparatively large coefficients for public sector wages. Figure 2 shows the second cointegrating relation. The vector has a comparatively large coefficient for private sector wages. The third eigenvector produces a relation that is nonstationary according to the tests (Figure 3). 


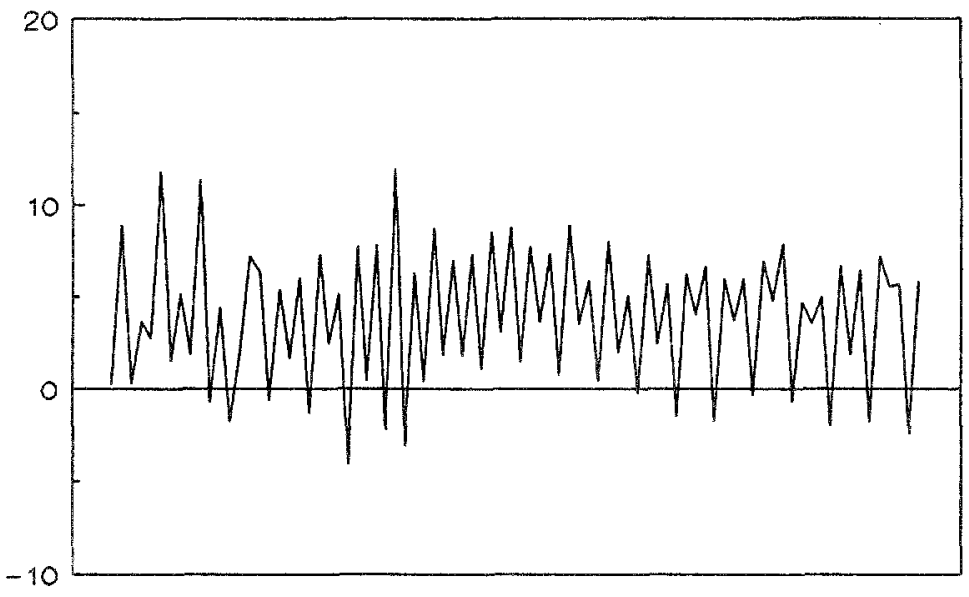

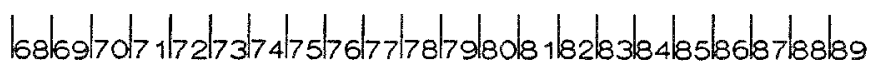

Fig. 1. The first cointegrating relation, the basic model, $62.4 w_{t}^{c}-61.8 w_{t}^{l}+1.3 w_{t}^{p}$

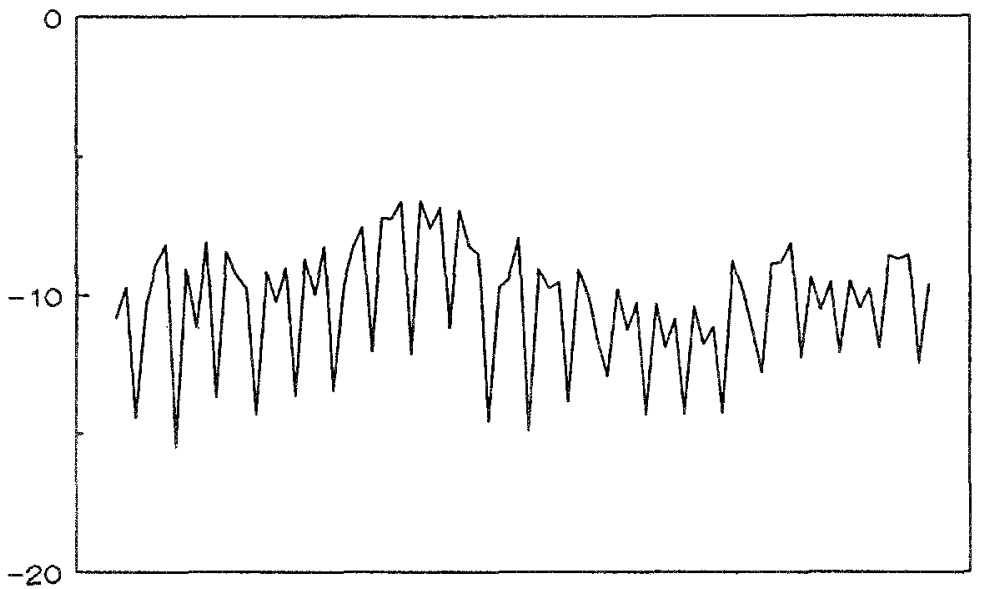

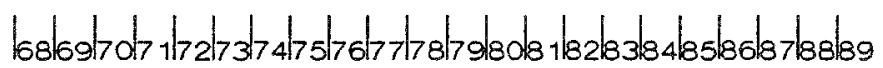

Fig. 2. The second cointegrating relation, the basic model, $-6.2 w_{t}^{c}-26.4 w_{t}^{i}+30.5 w_{t}^{p}$

The figures suggest that there is seasonal variation. The model is, however, specified so that the seasonals are outside the long-run relations. Instead they are part a part of the short-run dynamics. Table $A 1$ presents the estimated seasonal effects for the conditional model with the other estimates capturing the short-run and long-run dynamics. 


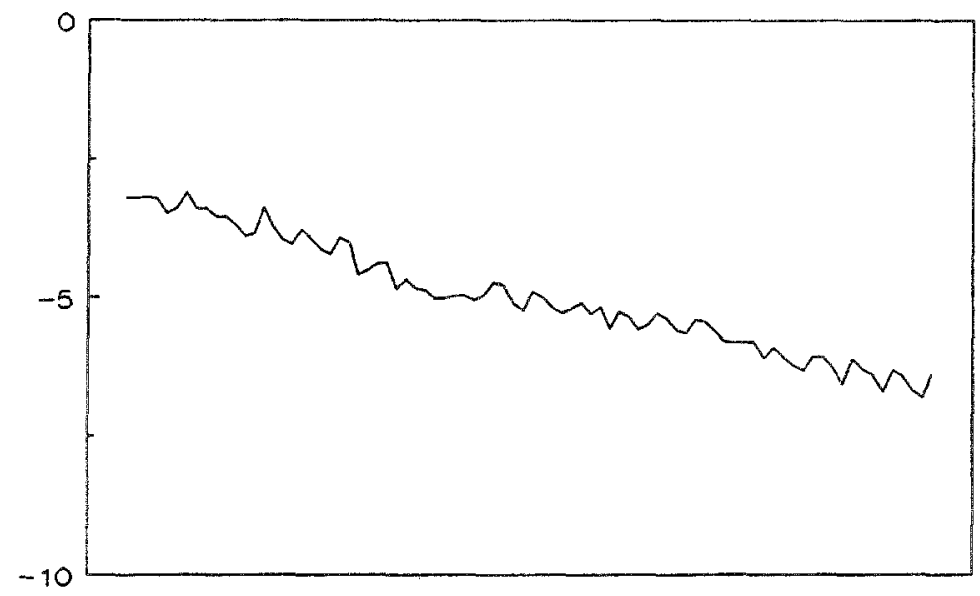

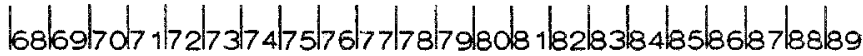

Fig. 3. The series from the third eigenvector, the basic model, $3.3 w_{t}^{c}+0.5 w_{t}^{l}-5.3 w_{i}^{p}$

Table A1. The estimates of the conditional model

\begin{tabular}{lrr}
\hline & $\begin{array}{l}\text { central government } \\
\text { wage changes }\end{array}$ & $\begin{array}{c}\text { local government } \\
\text { wage changes }\end{array}$ \\
\hline central government & -0.825 & 0.213 \\
wage changes, $t-1$ & $(5.65)$ & $(1.93)$ \\
central government & -1.066 & 0.308 \\
wage changes, $t-2$ & $(5.35)$ & $(2.05)$ \\
local government & 0.067 & -0.827 \\
wage changes, $t-1$ & $(0.34)$ & $(5.59)$ \\
local government & 0.524 & -0.741 \\
wage changes, $t-2$ & $(2.06)$ & $(3.86)$ \\
private sector & 0.634 & 0.474 \\
wage changes, $t$ & $(3.25)$ & $(3.22)$ \\
private sector & 0.081 & 0.258 \\
wage changes, $t-1$ & $(0.35)$ & $(1.45)$ \\
private sector & 0.298 & 0.142 \\
wage changes, $t-2$ & $(1.38)$ & $(0.88)$ \\
\hline central government & -1.070 & 0.277 \\
wage level, $t-2$ & $(4.25)$ & $(1.46)$ \\
local government & 0.710 & -0.622 \\
wage level, $t-2$ & $(2.65)$ & $(3.06)$ \\
private sector & 0.311 & 0.335 \\
wage level, $t-2$ & $(2.49)$ & $(3.56)$ \\
\hline
\end{tabular}


Table AI (cont.)

\begin{tabular}{lcc}
\hline & $\begin{array}{l}\text { central government } \\
\text { wage changes }\end{array}$ & $\begin{array}{l}\text { local government } \\
\text { wage changes }\end{array}$ \\
\hline constant & 0.188 & 0.106 \\
& $(3.78)$ & $(2.82)$ \\
seasonal 1 & -0.187 & 0.066 \\
& $(2.09)$ & $(0.97)$ \\
seasonal 2 & -0.002 & 0.065 \\
& $(0.02)$ & $(0.87)$ \\
seasonal.3 & 0.118 & 0.308 \\
& $(1.62)$ & $(5.60)$ \\
\hline
\end{tabular}

Note: Absolute $t$-values within parentheses.

\section{References}

Ahn SK, Reinsel GC (1990) Estimation for partially nonstationary multivariate autoregressive modeis. Journal of the American Statistical Association 85:815-823

Aukrust $O$ (1977) Inflation in the open economy: A norwegian model. Artikler No 96, Statistisk Sentralbyrå, Oslo

Akaike H (1969) Fitting autoregressive models for prediction. Annals of the Institute of Statistical Mathematics 21:243-247

Box GEP, Pierce DA (1970) Distribution of residual autocorrelations in autoregressive-integrated moving average time series models. Journal of the American Statistical Association 65:1509_ 1526

Calmfors L (1978) Prices, wages and employment in the open economy. Monograph No 10, IIES, Stockholm

Campbell JY, Perron P (1991) Pitfalls and opportunities: What macroeconomists should know about unit roots. In: Blanchard OJ, Fisher S (eds) NBER Macroeconomics Annual 1991, MIT Press, Cambridge, MA

Edgren G, Faxén K-O, Odhner C-O (1973) Wage formation and the economy. London, Allen \& Unwin

Engle RF, Granger CWJ (1987) Co-integration and error correction: Representation, estimation, and testing. Econometrica 55:251-276

Hannan EJ, Quinn BG (1979) The determination of the order of an autoregression. Journal of Royal Statistical Society, Series B $41: 190-195$

Holmlund B, Ohisson H (1992) Wage linkages between private and public sectors in Sweden. Labour 6(2):3-17

Hosking JRM (1980) The multivariate portmanteau statistic. Journal of the American Statistical Association 75:602-608

Hylleberg S, Engle RF, Granger, CWJ, Yoo BS (1990) Seasonal integration and cointegration. Journal of Econometrics 44:215-238

Jacobson $T$ (1991) On the determination of lag order in vector autoregressions of cointegrated systems. Research Report 1991:4, Department of Statistics, Uppsala University

Jacobson T (1992) Simulating small-sample properties of the maximum likelihood cointegration 
method: Estimation and testing. Research Report 1992:3, Department of Statistics, Uppsala University

Jacobson T, Larsson R (1991) Numerical aspects of a likelihood ratio test statistic for cointegrating rank. Research Report No 163, Institute of Actuarial Mathematics and Mathematical Statistics, Stockholm University

Jarque CM, Bera AK (1980) Efficient tests for normality, homoscedasticity and serial independence of regression residuals. Economics Letters 6:255-259

Johansen S (1988) Statistical analysis of cointegration vectors. Journal of Economic Dynamics and Control 12:231-254

Johansen S (1991) Estimation and hypothesis testing of cointegration vectors in Gaussian vector autoregressive models. Econometrica 59:1551-1580

Johansen S (1992) Cointegration in partial systems and the efficiency of single-equation analysis. Journal of Econometrics 52:389-402

Johansen S, Juselius K (1990) Maximum likelihood estimation and inference on cointegration - with applications to the demand for money. Oxford Bulletin of Economics and Statistics 52:169-210

Johansen S, Juselius K (1992) Testing structural hypotheses in a multivariate cointegration analysis of the PPP and the UIP for the UK. Journal of Econometrics $53: 211-244$

Kunst R, Neusser K (1990) Cointegration in a macroeconomic system. Journal of Applied Econometrics 5:351-365

Lindbeck A (1979) Imported and structural inflation and aggregate demand: The Scandinavian Model reconstructed. In: Lindbeck A (ed) Inflation and Employment in Open Economies, NorthHolland, Amsterdam

Mardia KV (1970) Measures of multivariate skewness and kurtosis with applications. Biometrika $57: 519-530$

Muscatelli VA, Hurn S (1992) Cointegration and dynamic time series models. Journal of Economic Surveys $6: 1-43$

Nymoen R (1989) Modelling wages in the small open economy: An error correction model of Norwegian Manufacturing Wages. Oxford Bulletin of Economics and Statistics 51:239-258

Rödseth A, Holden S (1990) Wage formation in Norway. In Calmfors L (ed) Wage formation and macroeconomic policy in the nordic countries, SNS, Stockholm and Oxford University Press, Oxford

Schwarz G (1978) Estimating the dimension of a model. Annals of Statistics 6:461-464

Warginger K-G (1991) Wage formation in the Scandinavian model. An empirical test on Swedish data with an error correction model. Department of Economics, Stockholm University, mimeo

First version received: April 1992

Final version received: June 1993 